\title{
Micro- to Fine-Scale ChEMICAl GRAdIENTS AND LAYERS IN STRATIFIED COASTAL WATERS
}

\author{
By Alfred K. Hanson, Jr. and Percy L. Donaghay
}

M ODELS OF BIOGEOCHEMICAL dynamics and chemical variability in coastal waters have traditionally relied on the assumption that small-scale mixing processes are sufficiently strong and isotropic to rapidly disperse centimeter to meter scale chemical gradients and thin layered vertical structure. Although this assumption of homogeneity may be reasonable in tidally wellmixed estuaries, or within the well-mixed surface and bottom layers of some stratified systems, it may not be generally applicable to stratified coastal waters (Donaghay et al., 1992). A number of naturally occurring physical, biological, and chemical processes have the potential to influence the development, maintenance, and dissipation of micro- $(\mathrm{cm}$ to $\mathrm{m})$ to finescale ( 1 to $10 \mathrm{~m}$ ) chemical structure in stratified coastal waters. Since micro- and fine-scale structure in temperature, salinity. and density distributions result from smallscale physical mixing processes (Osborn. 1998), it is plausible that the vertical distributions of dissolved chemicals should have similarly scaled variability. Biogeochemical activity focused within thin plankton layers (Donaghay et al., 1992: Cowles and Desiderio, 1993; Cowles et al., 1998) should also cause and be influenced by similarly scaled gradients in chemical concentration and reactivity. This has clearly been demonstrated for methane (Sieburth and Donaghay, 1993), mercury (Mason et al., 1993), and iron (O'Sullivan et al., 1997 ) in the oxic-anoxic transition zone of the lower basin of the Pettaquamscutt Estuary. However, field observations of microto fine-scale chemical variability associated with physical micro- and fine-structure

Alfred K. Hanson. Jr., and Percy L. Donaghay, Graduate School of Oceanography, University of Rhode Island. Narragansett. RI 02882, USA. and/or thin plankton layers have been limited in more open systems both by the difficulties in sampling at these scales and by the assumption that such structures cannot persist.

Sensitive in situ chemical profiling techniques, with the same spatial and temporal resolution as in situ physical and bio-optical profiling techniques, are required to evaluate the influence of smallscale physical mixing and biological processes on chemical distributions, reaction rates and transport. We have developed an electronic profiling and sampling system (Fig. la) with the capability for simultaneously sampling at centimeter scales the physical, biological, chemical, and bio-optical structure of the water column. The in situ analytical chemical capabilities of the profiling system include electrochemical sensors for dissolved oxygen and $\mathrm{pH}$ and a sensitive profiling chemical analyzer (PCA; Fig. 1b) that can measure dissolved nitrite and iron(II) down to nanomolar concentration levels. Herein we will first consider the rationale for expecting microto fine-scale structure in nitrite and iron(II), brieffy describe our technical approach, and then use high-resolution profiles collected in East Sound, WA, to illustrate the importance of such measurements to understanding chemical dynamics and impacts in stratified coastal systems.

\section{Rationale for Nitrite and Iron(II) Fine-Structure}

High-resolution measurements of dissolved nitrite and iron(II) were selected for this investigation because it was thought that their biological and chemical reactivity would lead to fine-scale chemical structure in stratified coastal waters. Nitrite and iron(II) were also chosen because their spectrophometric determination required a limited number of reagents and had rapid color development rates, simplifying adaptation for in situ vertical profiling.

Nitrite, a dynamic intermediate in the marine nitrogen cycle, is generally a trace constituent $(<50 \mathrm{nM})$ in euphotic surface waters because it is both assimilated by phytoplankton and photochemically reactive (Zafiriou and True, 1979; Grasshoff and Koroleff, 1983). The accumulation of nitrite $(>100-2,000 \mathrm{nM})$ in mid-depth and deeper coastal waters is thought to be controlled by the microbiological processes of nitrification (i.e., ammonia and nitrite oxidation) and denitrification (i.e., nitrate reduction), occurring within the water column and in surficial sediments (Seitzinger et al., 1980: Lipschultz et al., 1986).

Iron plays an essential role as a micronutrient in phytoplankton photosynthesis (Geider and La Roche. 1994). There is evidence that iron limitation may selectively influence the growth of some species of phytoplankton in coastal waters (Brand, 1991: Sunda and Huntsman, 1995). However, the complexities of the marine chemistry of iron have hindered the elucidation of its micronutrient role (Donaghay et al., 1991: Wells et al., 1995). Most of the iron in oxygenated coastal marine waters is present as insoluble hydrous iron(III) oxide colloids and larger particles, forms of iron that are not readily bioavailable. Dissolved iron(III) is usually present in trace (nanomolar) amounts. Dissolved iron(II) is a more soluble form of iron that is produced by microbial or chemical reduction within oxygen-depleted waters and in suboxic sedimentary porewaters, or by photochemical reduction within the euphotic zone (O'Sullivan et al., 1991, 1997). The rate of iron(II) oxidation back to the less soluble iron(III) form is dependent on the oxidation rate constant and reactant concentrations (Millero et al., 1987). The redox cycling of iron between less avail- 
Electronic Profiling and Sampling System

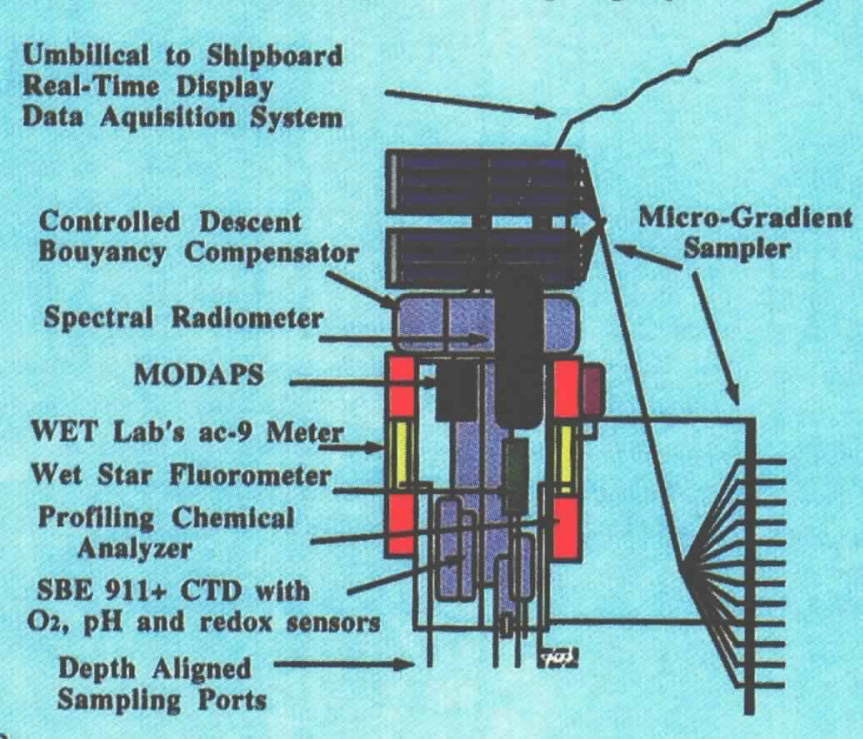

Profiling Chemical Analyzer

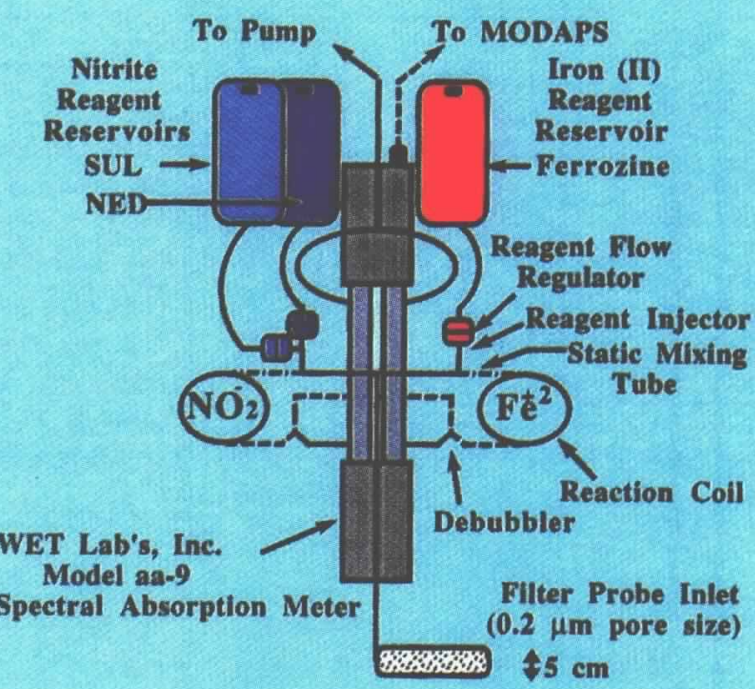

a

b

Fig. 1: Components of (a) the High-Resolution Electronic Profiling and Sampling System and (b) the Profiling Chemical Analyzer configured for dissolved nitrite and iron(II) measurements.

able forms of iron(III) and the more soluble forms of iron(II) results in elevated transient concentrations of reactive forms of iron(II) and iron(III) and can enhance the availability of iron for uptake by phytoplankton (Wells et al., 1995).

The location and intensity of the expected fine-structure should vary between nitrite and iron(II) because of differences in their transient nature (i.e., oxidation or consumption half-lives), sources and sinks, and sensitivities to other factors that vary on fine-scales. For example, the relatively slow rates of microbial production and loss of nitrite (Vaccaro, 1965) should lead to weak gradients except in areas where nitrogen assimilation by intense layers of phytoplankton rapidly generate nutriclines. In contrast, the relatively rapid rates and chemical control of iron(II) oxidation by ambient $\mathrm{pH}$ and oxygen levels, temperature, and salinity, should lead to vertical iron(II) structure being highly sensitive to recent input events and to the fine structure in these physicochemical factors. Testing these hypotheses presented a major analytical challenge because it required measuring the concentrations of nitrite and iron(II) in situ, at centimeter scales over the 3-4 orders of magnitude range of concentrations ( $\mathrm{nM}$ to $\mu \mathrm{M}$ ) expected in coastal waters. In addition, it required simultaneously measuring chlorophyll, temperature, salinity, oxygen, and $\mathrm{pH}$ at the same scales in order to evaluate the influence of these pa- rameters on the chemical structure, reaction rates, and fluxes.

\section{The PCA}

The PCA is comprised of a continuousflow, reagent-injection module connected to a dual-channel, nine wavelength, submersible spectral absorption meter (Fig. 1b). A WET Lab's model ac- 9 spectral absorption and attenuation meter (Moore $e t$ al., 1992) was customized to contain twin absorption channels (denoted as model aa9). The dual-channel reagent addition module was sized (i.e., pump, tubing sizes, flowrates, etc.) to match the geometry of the optical flow cells $(25-\mathrm{cm}$ pathlength, $1.2 \mathrm{~cm} \mathrm{ID,} \sim 25$-ml void volume) of the aa9. Seawater and reagents were drawn continuously through each channel of the PCA at $250 \mathrm{ml} / \mathrm{min}$ per channel by a gear pump located downstream. A $0.22-\mu \mathrm{m}$ pore size in-line filter with high-filtration surface area (Gelman maxicapsule) was fixed horizontally at the seawater inlet to the system. Reagents stored in 1.5-1 plastic bags were continuously injected at constant flowrates $(3-5 \mathrm{ml} / \mathrm{min})$ into the flowing seawater. The flow rates were controlled hydrodynamically by means of adjustable restricting orifices (Dial-A-Flo, Abbott Laboratories). After flow injection, the reagents and seawater were homogeneously mixed by passage through in-line static mixing tubes. After mixing, the reagents and analytes continued to react for $30 \mathrm{~s}$ during passage through the reaction coils before passing into the WET Labs aa-9 flowcells for detection.

Dissolved nitrite $\left(\mathrm{NO}_{2}^{-}\right)$and iron(II) $\left(\mathrm{Fe}^{+2}\right)$ were determined in situ spectrophotometrically using classical color-forming reagents: $N-1$ naphthylethylene-diamine and sulphanilamide for nitrite (Grasshoff and Koroleff, 1983) and Ferrozine reagent for iron(II) (Stookey, 1970). Differential absorption (units $=\mathrm{m}^{-1}$ ) measurements were utilized to determine nitrite and iron(II) using 540 and $560 \mathrm{~nm}$ as the respective analytical wavelengths and $650 \mathrm{~nm}$ as the reference wavelength. The improved optics, stable electronics, and longer pathlength of the WET Labs' model aa-9 resulted in the PCA being 10-100 times more sensitive than conventional laboratory autoanalyzers and spectrophotometers. The limits of detection for nitrite and iron(II) were 0.5 and $0.3 \mathrm{nM}$, respectively (estimated from 4 times the standard deviation of replicate blank readings). The fast data acquisition rate $(5.8 \mathrm{~Hz})$ of the WET Lab's aa-9 allowed $>5,000$ concentration readings to be acquired during a $15-\mathrm{min}$ cast to $25-\mathrm{m}$ depth (2 readings $/ \mathrm{cm}$ ). The PCA had the sensitivity and resolution to detect chemical gradients, at nanomolar to micromolar concentration levels, that occurred within a depth range of 10-20 cm with an instrument package drop-rate of $1-2 \mathrm{~m} / \mathrm{min}$.

The PCA was deployed as a component of a high-resolution electronic 


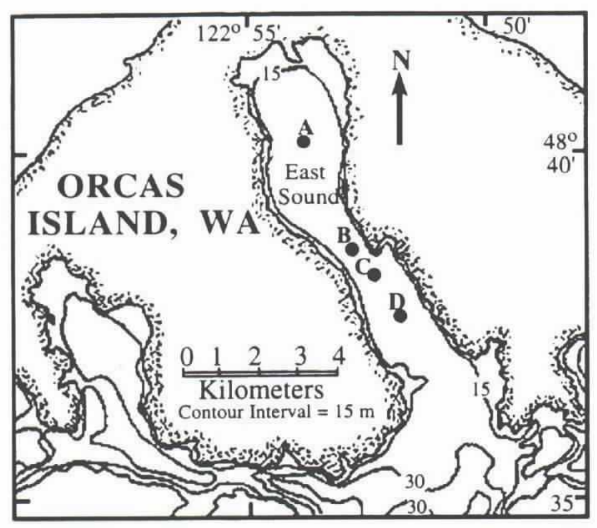

Fig. 2: Station locations and bathymetry of the coastal fjord study site, East Sound, WA.

profiling system (Fig. 1a) that included 1) a Sea-Bird Electronics, Inc., 911 plus CTD with fast response thermister, ducted flow cell, centimeter-scale resolving Digiquartz pressure sensor, and electrodes for $\mathrm{pH}$, redox potential, and dissolved oxygen; 2) a WET Labs, Inc., WETStar miniature chlorophyll fluorometer; 3) a Biospherical Instruments model PUV500 spectral UV and PAR radiometer; 4) a WET Labs model ac-9 spectral absorption and attenuation meter; and 5) pump-to-surface and microgradient sampling systems. A WET Labs, Inc., Modular Ocean Data Acquisition and Power System (MODAPS) was used to acquire and time stamp data from the in situ instruments, then transmit the data to the surface, where they were archived in a common file and displayed in real time.
Evidence for Fine-Scale Chemical Structure in East Sound

East Sound is a shallow fjord-like basin penetrating Orcas Island, located within the San Juan Archipelago of western Washington. The basin (Fig. 2) is $\sim 13 \mathrm{~km}$ long and 1-2 km wide and has a fairly uniform depth of $\sim 30 \mathrm{~m}$. A partial sill rises 10-15 $\mathrm{m}$ above surrounding bottom depths and extends about halfway across the southern entrance to East Sound. The physical dynamics of the primarily wind-driven circulation of East Sound are complex (Rattray, 1967). The stratified waters of East Sound, like many other seasonally stratified coastal environments, can have its vertical structure strongly modified by episodic wind events that can cause upwelling, downwelling, lateral advection, and/or
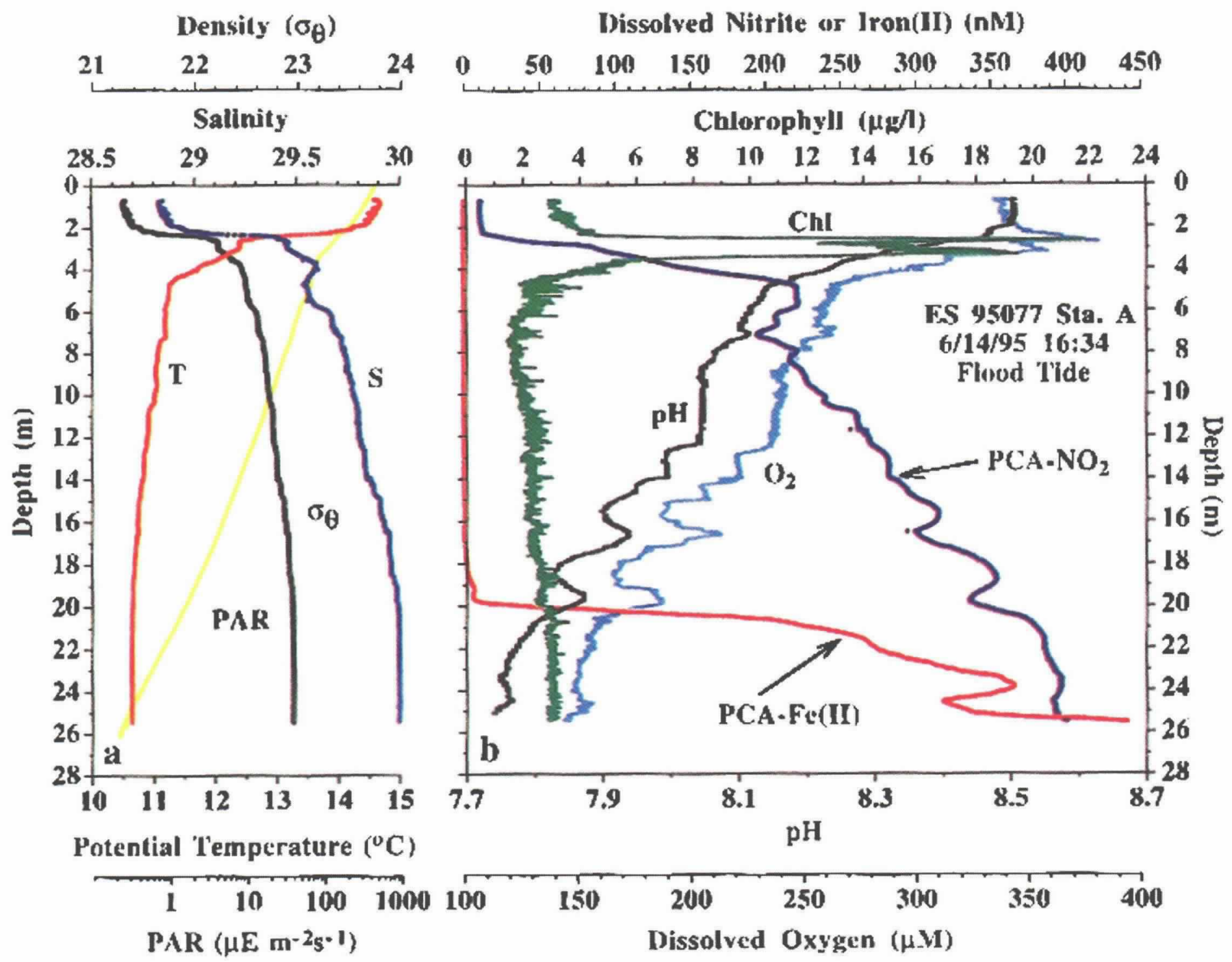

Fig. 3: Micro- to fine-scale chemical gradients associated with similarly scaled physical structures and thin chlorophyll fluorescence layers during flood tide at station A. 


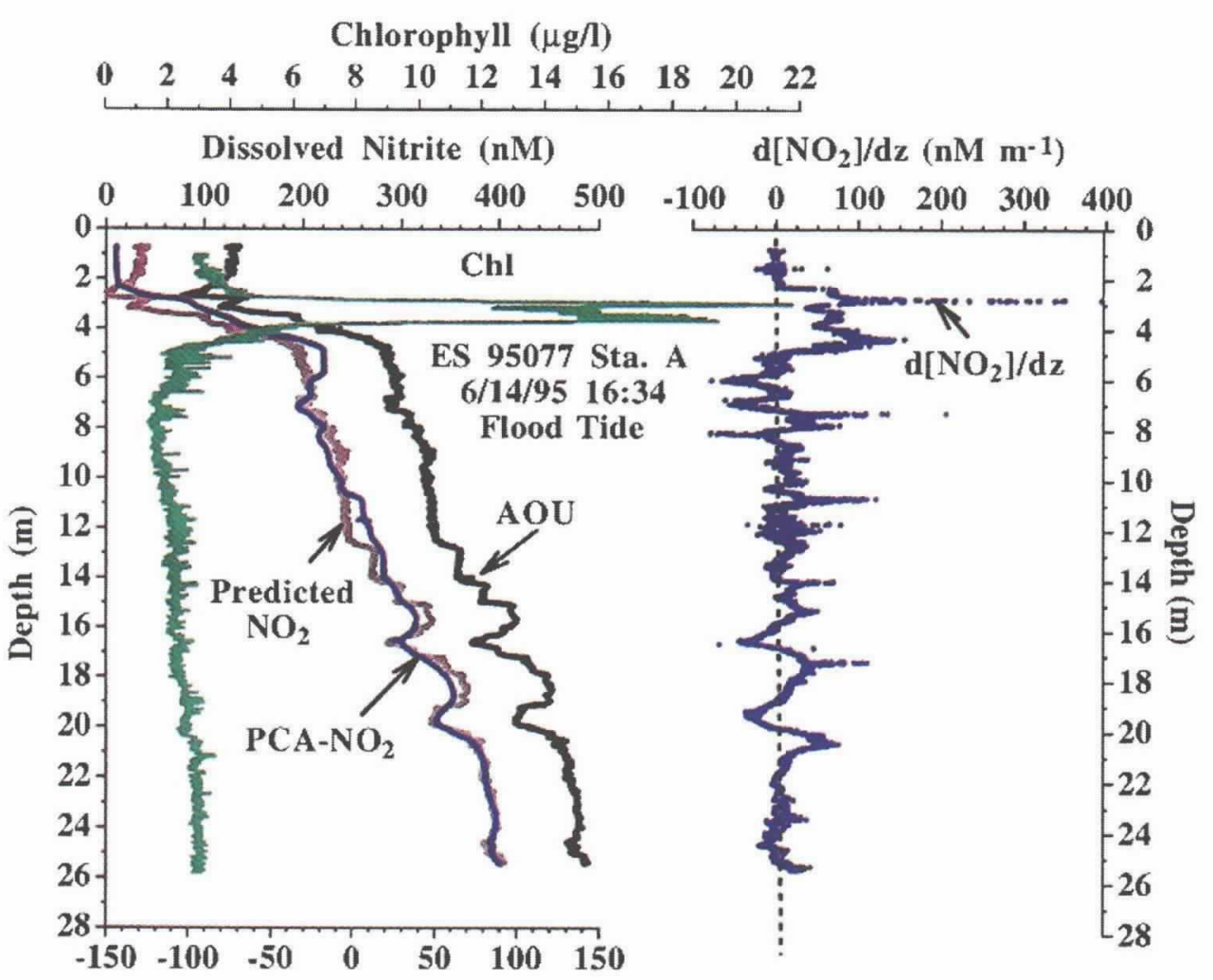

Apparent Oxygen Utilization $(\mu \mathrm{M})$

Fig. 4: Positioning of the thin chlorophyll fluorescence layer within the steep nitricline and the agreement between the fine-scale vertical distributions of $A O U$, nitrite, and model-predicted nitrite for the flood tide cast shown in Fig. 3.

mixed layer deepening. We have observed that such intermittent wind events can result in altered nutrient availability and lead to intense phytoplankton blooms. These blooms may be dispersed throughout the surface mixed layer and/or focused into thin layers within the pycnocline.

Vertical profiles, acquired at station A during flood tide in the late afternoon revealed considerable micro- to fine-scale structure and regions of strong gradients for temperature, salinity, density, chlorophyll a, dissolved oxygen, nitrite, iron(II), and $\mathrm{pH}$ (Fig. 3). The physical structure of the water column was typified by a $2-\mathrm{m}$ thick weakly stratified surface layer, a sharp pycnocline extending from $\sim 2$ to 4 $\mathrm{m}$, a more gradual increase in density (with fine-scale step-structure) through the mid-depth waters, and a well-mixed bottom layer (density gradients of $<0.001$ sigma theta $\mathrm{m}^{-1}$ ). The vertical phytoplankton structure was dominated by an intense thin chlorophyll a layer positioned within the pycnocline near $3 \mathrm{~m}$ depth. This thin plankton layer had a maximum thickness of $\sim 1 \mathrm{~m}$ and was comprised of several peaks of $10-40-\mathrm{cm}$ thickness. The estimated chlorophyll con- lated (linear correlation coefficients for profiles in Fig. 3b: $\mathrm{O}_{2}-\mathrm{pH}: \mathrm{r}^{2}=0.974, \mathrm{O}_{2}$ $\mathrm{NO}_{2}^{-}: \mathrm{r}^{2}=0.960$ and $\mathrm{pH}-\mathrm{NO}_{2}^{-}: \mathrm{r}^{2}=0.976$ ). This high degree of correspondence is attributed to the chemical stoichiometry of the photosynthetic production and organic matter remineralization reactions.

In an effort to quantify the nitrite gradient and its relationship to the thin chlorophyll a layer, we used the centimeter-scale nitrite data to calculate the nitrite concentration gradient as $\mathrm{d}\left[\mathrm{NO}_{2}^{-}\right] / \mathrm{dz}$. As indicated in Fig. 4, the nitrite gradient was extremely steep $\left(\mathrm{d}\left[\mathrm{NO}_{2}^{-}\right] / \mathrm{dz}=>300 \mathrm{nM} \mathrm{NO}_{2}^{-}\right.$ $\mathrm{m}^{-1}$ ) at the same depth as the thin chlorophyll a layer. This supports the hypothesis that phytoplankton uptake was controlling the position and intensity of the nitrite gradient. It is also consistent with the hypothesis that the vertical position and intensity of the thin phytoplankton layer was being controlled by the position and steepness of the nutricline. Although macronutrient determinations of water samples collected from discrete depths indicated that nitrate and ammonia were extremely low in the surface waters and increased rapidly in the region of the chlorophyll a layer, these discrete samples did not have the spatial resolution needed to accurately estimate the steepness and location of peak gradients. Rigorous testing of the hypothesis would require measuring these other potentially limiting macronutrients on the same centimeter scales as the nitrite.

Distinct submeter-scaled chemical gradients were also observed for nitrite, dissolved oxygen, and $\mathrm{pH}$ within the mid-depth and deeper waters for this flood tide cast. Two examples are the oxygen and $\mathrm{pH}$ maxima and corresponding nitrite minima present near 16.5 and $20 \mathrm{~m}$ depth (Fig. 3b). It is unlikely that these structures are the result of locally enhanced primary production because 1) they are not associated with peaks in chlorophyll a, 2) the light levels are low (1-10 $\left.\mu \mathrm{E} \mathrm{m}^{-2} \mathrm{~s}^{-1}\right)$, and 3) micromolar concentration levels of nitrate $(7-15 \mu \mathrm{M})$ and ammonia (4-6 $\mu \mathrm{M})$ were found at these depths. It is possible that fine-scale maxima and minima were produced within the water column by locally elevated rates of microbial remineralization of dissolved and particulate organic matter. An alternative explanation is that the corresponding midwater oxygen and $\mathrm{pH}$ minima, and nitrite maxima are chemical signals that originated near the sediment-water interface (via microbial remineralization) and were horizontally transported by physical processes (i.e., isopycnal transport) to these depths at sta- 


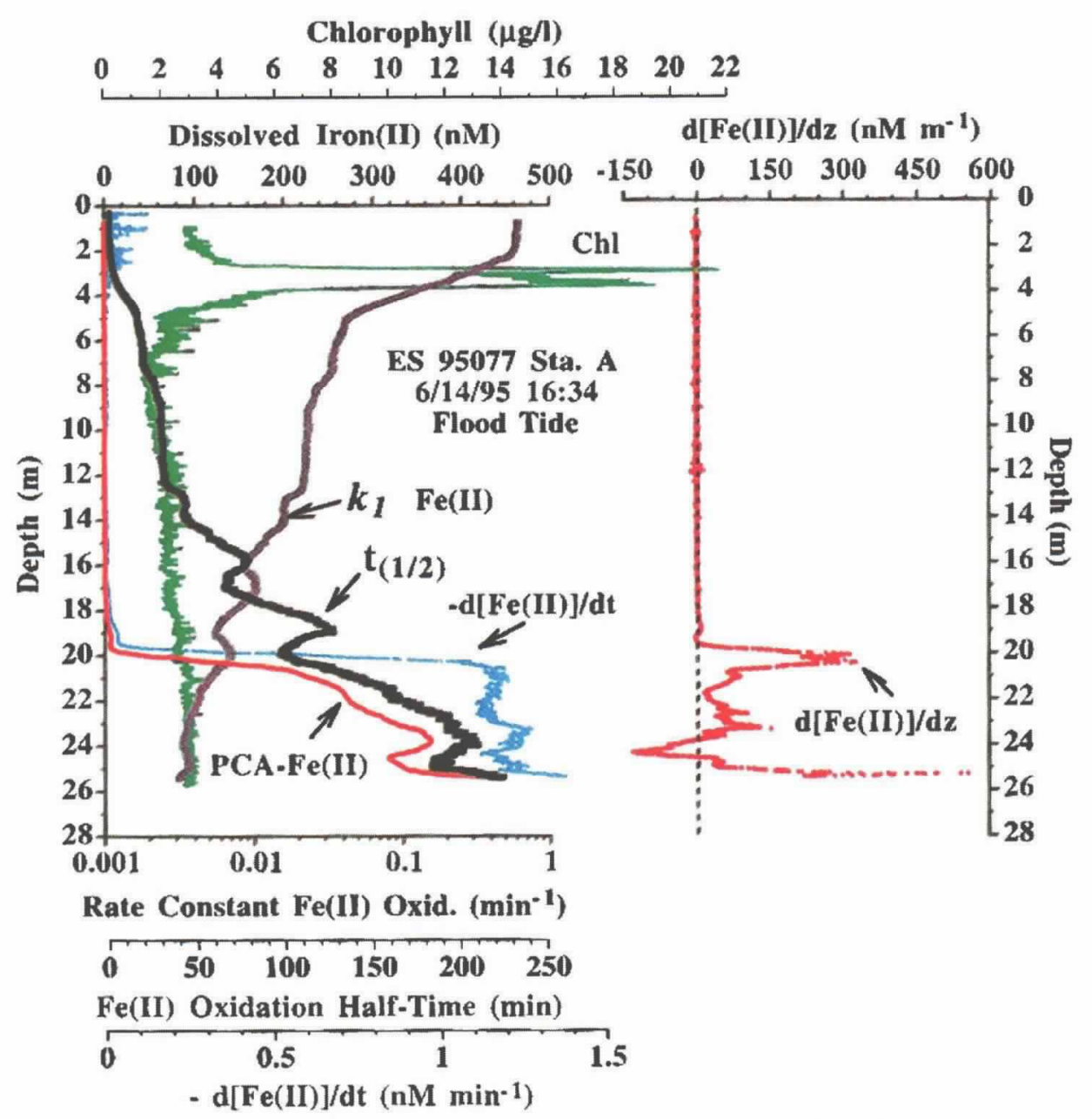

Fig. 5: Agreement between the steep iron(II) gradients detected in the bottom waters and model predictions of the vertical variability in the pseudo-first-order rate constants and half-lives for iron(II) oxidation, and the iron(II) oxidation rate for the flood tide cast shown in Fig. 3.

tion A. Although not readily discernible at the density scale shown in Fig. 3a, these mid-depth waters had characteristic density step-structures, thin (cm-scale) "sheets," with stronger gradients, separated by thicker (m-scale) "layers" with weaker or negligible gradients (Osborn and Cox, 1972; Gregg, 1975). The observed chemical fine-structure appears to be systematically related to these microscale and fine-scale physical discontinuities that Osborn (1998) attributes to localized vertical mixing and lateral intrusions, respectively. These observations are also consistent with the results of dye studies conducted in the Baltic Sea (Kullenberg, 1974, 1983). A slow rate of vertical mixing, relative to the rate of horizontal transport, may allow the chemical fine-structure to propagate along isopycnals and persist in the stratified waters.

Prediction of nitrite fine structure. If either of the remineralization explanations discussed above are correct, then the clas- lier profiler cast (Fig. 3b) allowed prediction of the approximate vertical position and slope of the primary nitricline and much of the fine-scale variability in the continuous nitrite profiles, which were obtained with the PCA during the earlier cast (compare predicted- $\mathrm{NO}_{2}^{-}$and $\mathrm{PCA}-\mathrm{NO}_{2}^{-}$ profiles in Fig. 4; Predicted- $\mathrm{NO}_{2}^{-}=$ 0.998(PCA-NO- $\left.\left.{ }_{2}^{-}\right)-3.18, r^{2}=0.974\right)$. Such a predictive capability is a testament to the sensitivity and accuracy of the PCA instrumentation for continuous, high-resolution measurements of dissolved nitrite in coastal waters. Perhaps more importantly, these results indicate that we should expect fine structure in nitrite profiles any time lateral transport or locally enhanced microbial activity lead to fine-scale structure in the AOU.

\section{Observed and Predicted Iron(II) Fine Structure}

The vertical structure of iron(II) was quite different at station $\mathrm{A}$ from the nitrite structure discussed above. Dissolved iron(II) was near the detection limit of the PCA $(<0.3 \mathrm{nM})$ in the upper water column, then increased rapidly at $\sim 20 \mathrm{~m}$ to higher concentrations (up to $440 \mathrm{nM}$ ) in the near bottom waters. The resulting micronutrient gradient was extremely steep $(\mathrm{d}[\mathrm{Fe}(\mathrm{II})] / \mathrm{dz}$ $=>500 \mathrm{nM} \mathrm{Fe}(\mathrm{II}) \mathrm{m}^{-1}$; see Fig. 5). In contrast to the tight correlation of the nitrite gradient with the thin chlorophyll layer in the upper water column, this steep gradient in dissolved iron(II) was unrelated to changes in chlorophyll fluorescence. Instead, it corresponded to the top of the well-mixed bottom boundary layer, suggesting that the elevated bottom water iron(II) levels might be the result of resuspension and mixing by bottom currents during this flood-tide cast. We made no attempt to collect samples for comparative laboratory analyses of dissolved iron(II) during this study because iron(II) oxidation rates were expected to be so fast that significant losses of iron(II) would occur during sample collection and preservation [see below for a discussion of iron(II) oxidation rates]. However, replicate samples were collected from discrete depths by the pump-to-deck and microgradient sampling systems and preserved by acidification for subsequent analytical determinations of dissolved and total acid reducible iron (O'Sullivan et al., 1997). Taken together, the in situ and laboratory results indicated that there was a substantial reservoir of iron in East Sound [ranges: 10-440 nM dissolved $\mathrm{Fe}(\mathrm{II}+\mathrm{III})$ and 50-2,929 nM 


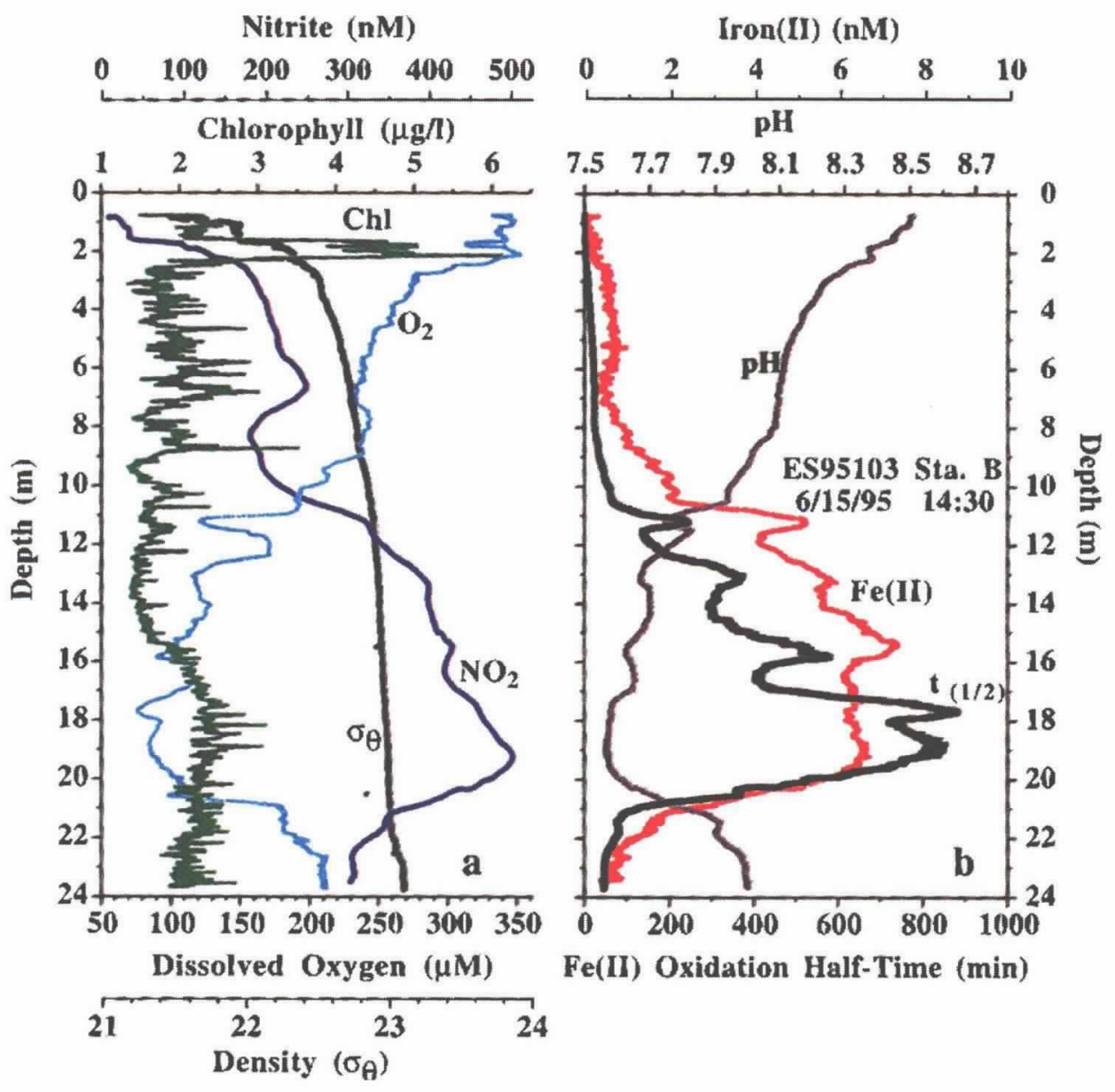

Fig. 6: Fine-scale vertical structure of physical, bio-optical, and chemical properties associated with a broad mid-depth oxygen minimum present during low tide at station $B$.

total Fe(II + III)], with the highest levels in the near bottom waters.

In the introduction, we hypothesized that the rapid rates and chemical control of iron(II) oxidation by ambient $\mathrm{pH}$, oxygen, temperature, and salinity levels should lead to vertical iron(II) structure being highly sensitive to recent input events and to fine structure in the physicochemical factors that control the oxidation rate. If the variably elevated levels of PCAiron(II) detected in near bottom waters was the result of a physical mixing event providing a flux of iron(II) into the overlying waters, then the iron(II) released would eventually be oxidized, transported, and accumulated as colloidal and particulate iron oxides within the mid-depth and deeper waters. The kinetics of the oxidation of iron(II) have been well studied in the laboratory, as a function of $\mathrm{pH}$, dissolved oxygen, temperature, and salinity (Millero et al., 1987). The pseudo-firstorder rate constant, $k_{l}$, for the rate equation $-d[\mathrm{Fe}(\mathrm{II})] / d t=k_{/}[\mathrm{Fe}(\mathrm{II})]$, encompasses the effects of these four parameters and is a first degree function of the oxygen concentration and second degree function of the $\mathrm{pH}$. The effects of salinity (expressed as ionic strength: $I=0.0199 \mathrm{~S}$ ) and temperature $\left({ }^{\circ} \mathrm{K}\right)$ on the overall rate constant, $k$, for the rate equation $-d[\mathrm{Fe}($ II) $] / d t$ $=k[\mathrm{Fe}(\mathrm{II})]\left[\mathrm{O}_{2}\right]\left[\mathrm{OH}^{-}\right]^{2}$ can be estimated from the relationship $\log k=21.56-$ $1545 / \mathrm{T}-3.29 \mathrm{I}^{(1 / 2)}+1.52 \mathrm{I}$. These algorithms conveniently allow the estimation of $k$ and $k_{l}$ from field data. The simultaneous measurement of all five parameters $\left[\mathrm{S}, \mathrm{T}, \mathrm{pH}, \mathrm{O}_{2}\right.$, and $\left.\mathrm{Fe}(\mathrm{II})\right]$ in East Sound provided us with a unique opportunity to test the real-world applicability of this kinetic model for iron(II) oxidation, developed by Millero and co-workers, and an independent check on the validity of the $\mathrm{Fe}$ (II) fine-structure detected by the PCA.

The continuous salinity, temperature, oxygen, and $\mathrm{pH}$ data from Fig. 3 were used to estimate the vertical variability for the pseudo-first-order rate constant $\left(k_{l}\right)$ for iron(II) oxidation in the East Sound water column (Fig. 5). Potential effects due to the complexation of iron(II) by organic lig- ands or the oxidation of iron(II) by hydrogen peroxide (Millero et al., 1987; Millero and Sotolongo, 1989) were ignored for these approximations. The estimated pseudo-first-order rate constant decreased systematically with depth by over two orders of magnitude for this cast. The calculated half-lives for iron(II) oxidation $\left(\mathrm{t}_{(1 / 2)}=\right.$ $\ln 2 \cdot k_{l}^{-l}$ ) ranged from $\sim 1$ min within the well oxygenated surface waters to $>200$ min near the benthic boundary. If iron(II) was introduced (e.g., pore water fluxes, sediment-water interactions, or photochemical reduction) into waters characterized by slower oxidation rates (longer oxidation half-lives), then the iron(II) signal would persist for a longer time period than in the surface waters. The longer half-live estimates for iron(II) oxidation in the near bottom waters are the combined result of the cooler temperatures, reduced $\mathrm{pH}$ values, and lower dissolved oxygen contents. These oxidation rate estimates also suggest that there was micro- to fine-scale variability in the iron(II) oxidation potential of the stratified waters of East Sound.

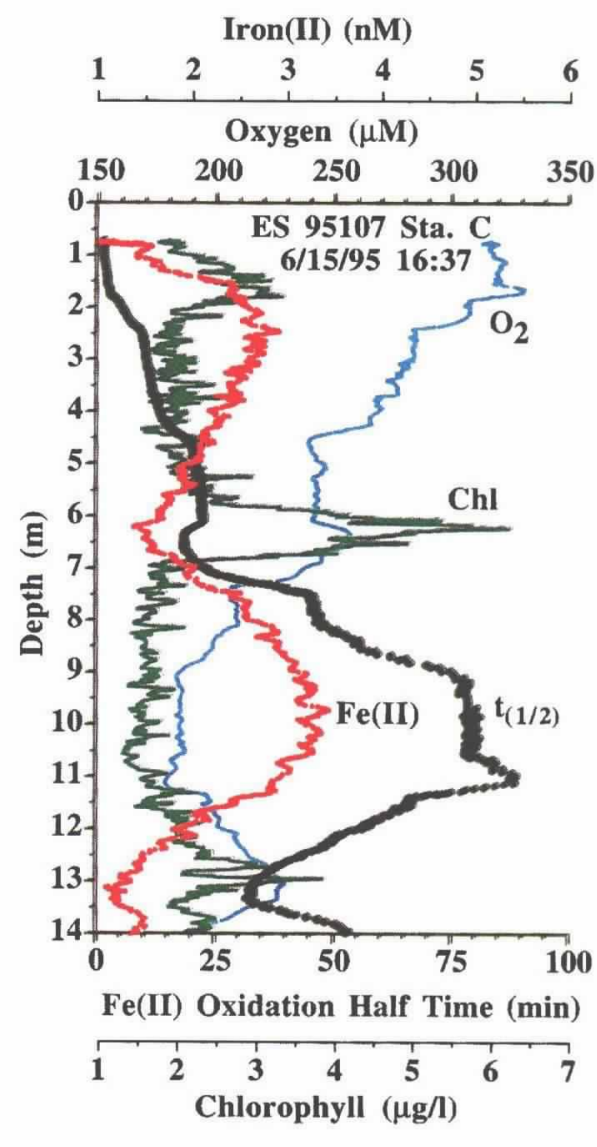

Fig. 7: Association of thin chlorophyll fluorescence layers with micro- to finescale gradients of oxygen, nitrite, iron(II), and model-predicted half-lives for iron(II) oxidation during flood tide at station $C$. 
Comparison of the half-lives for iron(II) oxidation with the PCA-iron(II) distribution showed a remarkable degree of correspondence (Fig. 5). Higher concentrations of dissolved iron(II) were only detected in waters with slower iron(II) oxidation rates. The estimated oxidation rate for iron(II), $-d[\mathrm{Fe}(\mathrm{II})] / d t$, was greatest $\left(1.1-1.4 \mathrm{nM} \mathrm{min}{ }^{-1}\right)$ within the iron(II)-containing waters that comprised the benthic boundary layer. The estimated oxidation rate for iron(II) increased very sharply near the top of the benthic boundary layer $(\sim 20 \mathrm{~m})$ and associated steep iron(II) gradient $(\mathrm{d}[\mathrm{Fe}(\mathrm{II})] / \mathrm{dz}$ $=\sim 300 \mathrm{nM} / \mathrm{m}$ ), indicating that iron(II) was more effectively oxidized within this region, than in the near bottom waters containing more iron(II). Because the most likely source of the high iron(II) in the bottom waters is from sediment porewater fluxes and tidal resuspension of sediments, it should not be surprising that another region characterized by a steep iron(II) gradient is near the sediment interface. The iron(II) fine-structure and strong gradients, detected by the PCA at this station, are predicted to be present by the underlying iron(II) oxidation kinetics.

\section{Spatial and Temporal Variation in Fine-Scale Structure}

There was considerable spatial and temporal variability in chemical compositions. predicted reaction rates, and fine-scale gradients in the waters of East Sound. This was particularly evident for a late afternoon profiler deployment at station B (Fig. 6) that was characterized by a broad middepth minima (12-22 $\mathrm{m}$ ) in dissolved oxygen and $\mathrm{pH}$ and corresponding maxima in dissolved nitrite and iron(II). The PCAiron(II) levels increased from subnanomolar surface values to $\sim 7 \mathrm{nM}$ within the mid-depth waters with lower oxygen contents, then declined rapidly to subnanomolar levels in deep waters. In contrast to station $\mathrm{A}$, the increases in iron(II) at station $\mathrm{B}$ cannot be attributed to iron(II)-rich bottom waters being recently mixed upward by tidal flows. The rapid decline in iron(II) below $20 \mathrm{~m}$ corresponds to a rapid increase in oxygen and $\mathrm{pH}$ at that depth. The calculated rate constants for iron(II) oxidation indicated that the lower $\mathrm{pH}$ and oxygen contents within the midwater minimum extended the half-lives for iron(II) oxidation considerably (to $>800 \mathrm{~min}$ ). This not only suggests that this feature should persist for some time, but that it could be derived from an interaction with the ben- thos (or other source) that occurred several days earlier, and then was advected as a midwater layer to this location. In addition to the steep gradients and broad iron(II) maximum, several submeter-scale maxima were also evident. As at station A, the calculated half-life for iron(II) oxidation shows submeter-scale maxima that precisely correspond to $\mathrm{Fe}(\mathrm{II})$ concentration maxima. Again, the fine-scale structure and sharp gradients are qualitatively consistent with the underlying iron oxidation kinetics.

\section{Biological Control of Iron(II) Gradients}

The chlorophyll fluorescence, oxygen, and PCA-iron(II) profiles, from a late afternoon deployment at station C (Fig. 7), demonstrate that thin plankton layers (located near 1.5, 6, and $13 \mathrm{~m}$ depth) can exert a similarly scaled influence on dissolved oxygen levels, and both the estimated oxidation rate and the trace concentration levels of dissolved iron(II). The fine-scale minima for estimated iron(II) oxidation half-lives can be attributed to focused photosynthetic carbon dioxide uptake (higher $\mathrm{pH}$ ) and oxygen evolution within the thin phytoplankton layers. The corresponding minima in iron(II) concentrations may be due to locally enhanced rates for iron(II) oxidation and/or direct bioassimilation of dissolved iron(II). Conversely, the midwater (9-11 m) maximum in iron(II) corresponds both to a maximum in the expected half-life for iron(II) oxidation and to a minimum in phytoplankton chlorophyll and thus potentially lower direct bioassimilation. Iron redox cycling and phytoplankton growth appear to be closely coupled in East Sound.

\section{Discussion}

The continuous vertical profiles obtained with the high-resolution electronic profiling system and the profiling chemical analyzer in East Sound demonstrate that fine-scale chemical gradients and chemically distinct thin layers can exist in stratified coastal environments. The fine-scale gradients detected for nitrite were quantitatively related to similarly scaled gradients in apparent oxygen utilization. The fine-scale gradients detected for iron(II) were consistent with the similarly scaled gradients predicted for the pseudo-firstorder rate constant for iron(II) oxidation. The mechanisms for the fine-scale structure observed in the water column included 1) focused chemical uptake or release within thin phytoplankton layers and 2 ) the interaction of physical mixing and transport processes with chemical fluxes from the sediment-water interface. Isopycnal transport may be an important mechanism to supply iron and other nutrients from the benthos to high-biomass, thin plankton layers in East Sound. WA.

It is evident from the East Sound results that the vertical depth resolution of the PCA, for changes in dissolved nitrite and iron(II) concentrations, was approaching the depth-resolution of the electrochemical $\mathrm{pH}$ and oxygen sensors that were co-deployed with the electronic profiling system. Whereas many electrochemical sensors and some submersible chemical analyzers may have the required response times and sensitivity to detect micro- to fine-scale chemical gradients in stratified coastal waters, they generally have not been applied for that purpose (Johnson et al., 1986, 1990, 1992; Taylor et al., 1993; Johnson and Jannasch, 1994; Klinkhammer, 1994). The faster package descent rates that have commonly been used during coastal and offshore investigations with CTDs and submersible chemical analyzers $\left(10-40 \mathrm{~m} \mathrm{~min}^{-1}\right.$ versus the 1-2 $\mathrm{m} \mathrm{min}^{-1}$ used in this study) have typically precluded the detection of submeter-scale variability in the water column by the submersible chemical instrumentation.

The enhanced sensitivity of the PCA for nitrite and iron(II) allowed us to document the chemical fine-structure and the presence of transient iron(II) within the water column that has passed undetected by traditional water sampling and analytical methodologies. For example, all the iron(II) fine-structure detected by the PCA in the upper portions of the East Sound water column was below the detection limit $[<20 \mathrm{nM}$ iron(II)] of the sampling and analytical methodology used by Murray and Gill (1978) in their earlier investigation of the geochemistry of iron in Puget Sound waters. This underscores the importance of being able to determine the concentrations of reactive chemicals at the trace levels that influence chemical and biological rates, and with sufficient resolution to define the gradients as they really occur in nature. With the high-resolution electronic profiling and PCA technologies, we now have the capability to resolve chemical gradients at the small spatial and temporal scales required to investigate the relative importance of chemical processes in the creation and maintenance of thin biologically productive layers and conversely, 
the influence of such layers on chemical distributions, fluxes, and reaction rates.

\section{Future Directions}

There are important chemistry-related questions that need to be addressed concerning the dynamics of thin plankton layers. What mechanistic roles do nutrient recycling and availability play in thin plankton layer dynamics? Are episodic variations in nutrient gradients, driven by and coupled to dynamic meteorological and physical processes, critically important to the development. persistence, and behavior of thin plankton layers? How significant are the influences of thin plankton layers on the distributions of inorganic and organic chemicals and on their biologically mediated reaction rates within coastal waters? Our present difficulty in adequately answering these questions illustrates the sparseness of our chemical data on the thin plankton layers phenomena. This short-coming is partly due to the limited availability of high-resolution submersible chemical sensors and analyzers that can interface with contemporary CTD and bio-optical profiling systems. The development of a high-resolution, multinutrient profiling analyzer, would allow us to more adequately characterize the nutrient supply to high-biomass, thin plankton layers and provide the parameterization of the nutrient field that is required to develop and test predictive models for thin plankton layer behavior in coastal waters.

\section{Acknowledgements}

Funding for this research was provided by the Office of Naval Research grants $\mathrm{N}$ 00014-94-1-0561 to A.K. Hanson and N00014-95-1-0225 to P.L. Donaghay. The technical assistance of Robert Griffin with PCA calibration, iron and nutrient determinations and data processing is gratefully acknowledged. We thank Casey Moore (WET Labs, Inc.), Ron Zaneveld, Jennifer Prentice, James Sullivan, and Mike Twardowski for their assistance in this work. We also thank Tim Cowles, Frank Millero, and the anonymous reviewers for their valuable comments.

\section{References}

Brand, L.E., 1991: Minimum iron requirement of marine phytoplankton and the implications for the biogeochemical control of new production. Limnol. Oceanogr., 36, 1756-1771.

Cowles, T.J. and R.A. Desiderio, 1993: Resolution of biological micro-structure through in situ fluorescence emission spectra. Oceanography. 6, 105-111.

Cowles, T.J., R.A. Desiderio and M.-E. Carr, 1998: Oceanography, 11:1, 4-9.

Donaghay, P.L., P.S. Liss, R.A. Duce. D.R. Kester, A.K. Hanson, T. Villareal, N.W. Tindale and D.J. Gifford. 1991: The role of episodic atmospheric nutrient inputs in the chemical, and biological dynamics of oceanic ecosystems. Oceanography, 4, 62-70.

H.M. Rines and J.M. Sieburth, 1992: Simultaneous sampling of fine-scale biological, chemical, and physical structure in stratified waters. Arch. Hydrobiol., 36, 1-14.

Geider, R.J. and J. La Roche. 1994: The role of iron in phytoplankton photosynthesis, and the potential for iron-limitation of primary productivity in the sea. Photosynthesis Res., 39. 275-301.

Grasshoff. K. and F. Koroleff, 1983: Determination of nutrients. In: Methods of Seawater Analysis. K. Grasshoff, M. Ehrhardt and K. Kremling, eds. Verlag Chemie, Weinheim, Germany, 125-187.

Gregg, M.C.. 1975: Oceanic fine, and micro-structure. Rev. Geophys. Space Phys., 13, 586591.

Johnson, K.S., C.L. Beehler and C.M. SakamotoArnold, 1986: A submersible flow analysis system. Analytica Chimica Acta. 179. 245257.

K. Coale and H.W. Jannasch. 1992: Analytical Chemistry in Oceanography. Anulytical Chem., 64, 1065A-1075A.

and H.W. Jannasch, 1994: Analytical chemistry under the sea surface: monitoring ocean chemistry in situ. Naval Res. Rev.. 3. 4-12.

, C.M. Sakamoto-Arnold and C.L. Beehler, 1990: Continuous determination of nitrate concentrations in situ. Deep-Sea Res., 36, 1407-1413.

Klinkhammer, G.P.. 1994: Fiber optics spectrometers for in situ measurements in the oceans: the ZAPS Probe. Mar. Chem., 47. 13-20.

Kullenberg, G., 1974: Investigation of small-scale vertical mixing in relation to the temperature structure in stably stratified waters. Adv. Geophysics, 18, 339-351.

1983: Physical processes. In: Pollutant Transfer and Transport in the Sea. G. Kullenberg. ed. CRC Press, Boca Raton, FL. pp. 2-89.

Lipschultz, F., S.C. Wofsy and L.E. Fox, 1986: Nitrogen metabolism of the cutrophic Delaware River ecosystem. Limnol. Oceanogr., 31. 701-716.

Mason, R.P., W.F. Fitzgerald. J. Hurley, A.K. Hanson, Jr., P.L. Donaghay and J.M. Sieburth. 1993: Mercury biogeochemical cycling in a stratified estuary. Limnol. Oceanogr., 38,
$1227-1241$

Millero. F.J. and S. Sotolongo, 1989: The oxidation of $\mathrm{Fe}(\mathrm{II})$ with $\mathrm{H}_{2} \mathrm{O}_{2}$ in seawater. Gershimica et Cosmochimica Acta, 53, 1867-1873.

S. Sotolongo and M. Izaguirre, 1987: The oxidation kinetics of $\mathrm{Fe}(\mathrm{II})$ in seawater. Geochimica et Cosmochimica Arta, 51 , 793-801.

Moore, C.. J.R.V. Zaneveld and J.C. Kitchen. 1992: Preliminary results from an in situ spectral absorption meter. In: Oce'an Optics $X I$. G.D. Gilbert. ed. Proc. SPIE 1750 . $330-337$.

Murray, J.W. and G. Gill, 1978: The geochemistry of iron in Puget Sound. Geochimica et Cosmochimica Acta, 42, 9-99.

Osborn, T.R., 1998: Oceanography, 11:1, 36-43. and C.S. Cox, 1972: Oceanic fine-structure. Geophys. Fluid Dyn., 3, 321-345.

O'Sullivan. D.W.. A.K. Hanson. Jr. and D.R. Kester. 1997: The distribution and redox chemistry of iron in the Pettaquamscutt Estuary. Estuarine Coastal Shelf Sci. 45, 769-788.

A.K. Hanson, Jr., W. Miller and D.R. Kester, 1991: Measurement of $\mathrm{Fe}(\mathrm{II})$ in Equatorial Pacific Surface Seawater. Limnol. Oceanogr., 36, 1727-1741.

Rattray, M., Jr.. 1967: Some aspects of the dynamics of circulation in fjords. In: Estuaries. G.H. Lauff, ed. AAAS, Washington, DC., $52-62$.

Redfield, A.C., 1942: The processes determining the concentration of oxygen. phosphate, and other organic derivatives within the depths of the Atlantic Ocean. Pap. Phys. Oceanogr. Meteor., 9, 1-22.

Seitzinger, S.P., S.W. Nixon and M.E.Q. Pilson, 1980: Denitrification and $\mathrm{N}_{2} \mathrm{O}$ production in nearshore marine sediments. Gerchimica et Cosmochimica Acta. H4, 1853-1860.

Sieburth, J.M. and P.L. Donaghay, 1993: Planktonic methane production and oxidation within the algal maximum of the pycnocline: seasonal fine-scale observations in an anoxic estuarine basin. Mar. Eiol. Prog. Ser.. 100, 3-15.

Stookey. L.L.. 1970: Ferrozine-a new spectrophotometric reagent for iron. Analytical Chem., 42, 779-781.

Sunda, W.G. and S. Huntsman, 1995: Iron uptake and growth limitation in oceanic and coastal phytoplankton. Mar. Chem., 50, 189-206.

Taylor. C.D., B.L. Howes and K.W. Doherty, 1993 : Automated instrumentation for time-series measurement of primary production and nutrient status in production-platform accessible environments. MTS J., 27, 32-44.

Vaccaro, R.F.. 1965: Inorganic nitrogen in seawater. In: Chemical Oceanography, Vol. I. J.P. Riley and G. Skirrow, eds. Academic Press. London, 365-408.

Wells, M.L.. N.M. Price and K.W. Bruland, 1995: Iron chemistry in seawater and its relationship to phytoplankton: a workshop report. Mar. Chem., 48, 157-182.

Zafiriou, O.C. and M.B. True, 1979: Nitrite photolysis in seawater by sunlight. Mar. Chem. 8 . 9-13. $\square$ 